\title{
Factors affecting efficiency of cotton producers in rural Khorezm, Uzbekistan: Re-examining the role of knowledge indicators in technical efficiency improvement
}

\author{
Aziz A Karimov
}

Correspondence:

az.karimov@cgiar.org

International Livestock Research Institute, 17A Nguyen Khang street, Hanoi, Vietnam

\section{Springer}

\begin{abstract}
Few efficiency studies, to date, have been conducted for Central Asian countries. This article fills the gap in the literature by conducting a frontier efficiency analysis using survey data obtained from the cotton producing farms in North-western Uzbekistan. The results of the restricted stochastic frontier model, which follows a three-stage procedure, demonstrate the presence of technical inefficiency in cotton production. The findings illustrate that the results from the traditional frontier models, which use black box tools, lead to biased outcomes. The model displays that farmers' educational background, farm size, water availability, the application of manure, access to formal credit, Water User Association's services, farmers' participation in off-farm work and poor drainage systems, significantly contribute to input use efficiency. A quantile regression also shows that knowledge indicators play a significant role in improving farmers' efficiency in cotton production. The impact of agricultural experience on technical efficiency is positive, but not significant, in the middle and higher efficiency percentiles. Interestingly, having a basic education is not sufficient in achieving higher efficiency, based on the results obtained. The findings suggest that the provision of agricultural training and the development of agricultural extension services will help farmers acquire new technologies and enhance their decision-making capabilities in farm production which subsequently improve resource use efficiency in cotton production.
\end{abstract}

Keywords: Stochastic frontier analysis; Cotton production; Explanatory factors; Three stage procedure

\section{Background}

Many developing countries rely on agriculture to support their poor populations. Consequently, the development of policies that target increasing agricultural productivity is the governments' typical domestic reaction to the challenge of reducing poverty and increasing food security in rural areas. While the adoption and dissemination of innovative farming practices eventually contribute to improvements in productivity and income (Awotide et al. 2013), effective resource use and a well-organized farm management are expected to boost their sustainability (Karimov 2012). In this respect, education is an essential factor that plays a key role, both in increasing the efficiency of resource utilization and in bettering the organization of farm.

(c) 2014 Karimov; licensee Springer. This is an Open Access article distributed under the terms of the Creative Commons Attribution License (http://creativecommons.org/licenses/by/2.0), which permits unrestricted use, distribution, and reproduction in any medium, provided the original work is properly cited. 
Welch (1970) states that education is a strong complement of most of the factors of production utilized in crop production. A recent macro study by Reimers and Klasen (2013) finds that education positively impacts agricultural productivity worldwide. At the micro level, many studies, including Mathijs and Vranken (2001), Alene and Hassan et al. (2003), and Assadullah and Rahman (2009), find a positive relationship between farmer education and efficiency. Other studies such as Llewellyn and Williams (1996) and Chirwa (2007), however, do not observe any significant connections. Hence, the prevailing literature is rather indecisive, which suggests a need for further research.

This study investigates the issue by analyzing survey data from Uzbekistan, which is a cotton producing transition country. In general, the support of agriculture in transition economies has entered a new phase, with large-scale structural adjustment programs that focus on agricultural transformations. Specific reforms included land tenure policies and farm restructuring, which have been extensively reviewed in the literature (Liefert and Liefert 2012). In this period, access to improved agricultural knowledge has become a priority because rural inhabitants who are not knowledgeable enough in farm production started obtaining agricultural land. New market mechanisms also required the acquiring of new sets of skills to run farms efficiently. In these regards, donor financed agricultural development programs stressed farmer supported educational programs and the establishment of extension services. To some extent, domestic rural policies also included launching agricultural training programs and improving the role of agricultural advisory service organizations. In other words, educating farmers to be efficient and productive under changing environment has become the primary concern for all.

Few efficiency analyses in the case of Central Asian (CA) countries (Uzbekistan, Kazakhstan, Tajikistan, Turkmenistan and Kyrgyzstan) have been conducted. One such work is by Tashrifov (2005), who estimated the technical efficiency (TE) of cotton producing regions in Tajikistan. While this study found production inefficiencies among the cotton regions of the country, it exercised regional aggregate data that might not carry valuable evidence for efficiency differentials at the farm level.

This work aims to fill the gap in the literature and contribute to the ongoing policy discussion with regards to improving resource use efficiency. The specific objectives of the article are threefold: a) to evaluate the TE of cotton producers using the theoretically consistent stochastic frontier model (SFM); b) to investigate the significance of some of the farm related factors that are believed to influence the households' input use in cotton production, and c) to re-examine impact of knowledge indicators on resource use efficiency.

\section{Cotton production in Uzbekistan}

Cotton continues to be the number one agricultural crop in Uzbekistan; it is considered a strategic commodity because of its standing as a source of rural employment and foreign exchange (Rudenko 2008). The country produces approximately 3.5 million metric tons of raw cotton and roughly 1.0-1.2 million metric tons of cotton fibre per annum. While these figures are relatively low, when compared with the ones achieved during the Soviet period, Uzbekistan is still considered a major world cotton producer and exporter (USDA 2012). 
Cotton production in the country is under state control. Hence, everything related to cotton has a national significance and priority. Achieving higher yields is a major concern for those involved in the entire cotton value chain. The primary burden of the crop, however, is still on the shoulders of farmers, who must meet annual production targets (state quotas). According to the contract between a farmer and the state, a farmer is committed to market $100 \%$ of the harvest obtained from the leased land to the state cotton ginneries (Aminova and Abdullayev 2009) at predetermined prices. In return, the state's semi-controlled organizations supply subsidized inputs through an extensive credit program. Since the price of the cotton is fixed (there is small price change depending on the quality), farmer can achieve higher margins only by increasing yields and efficiently using input resources. However, yield numbers at the country level illustrate that cotton production has decreased since independence (Guadagni et al. 2005; USDA 2012). This decline is believed, in part, due to the inefficient use of resources. Because the official statistics do not include resource use data, it is difficult to acquire accurate information about the intensity of resource utilization in cotton production. However, some reports discuss the over- or under-utilization of inputs. For example, according to ScanAgri Sweden AB for the ADB (2008), raw cotton produced per kilogram of fertilizer decreased from $11 \mathrm{~kg}$ to $8.8 \mathrm{~kg}$ between 1995 and 2005 (ADB 2008). Moreover, raw cotton in terms of per kilogram of fuel dropped by $1.2 \mathrm{~kg}$ over the same period. While these numbers are low when compared to other countries with analogous climate conditions, the cost of producing cotton is high. In this regard, the strengthening of the efficiency of cotton production is one of the key objectives of the government of Uzbekistan.

The study enlightens this issue in the context of frontier efficiency analysis by looking at some of the factors that are assumed to influence cotton production. It particularly stresses the role of knowledge indicators in efficiency improvements and empirically examines their significance. Overall, the study provides some interesting findings for the international audience by discussing the case of a transition country located in the CA.

\section{Methods}

\section{Study area}

The study was carried out in the Khorezm province of Uzbekistan. Khorezm belongs to the northern agro-ecological zone, according to the FAO (2003). It is situated in North-western Uzbekistan, in the southern part of Karakalpakistan, next to Turkmenistan. The province constitutes 6.1 thousand sq. km., or 1.3\%, of the country's territory. The province includes 10 districts and Urgench city, an administrative centre in the province.

The population of Khorezm is approximately 1.6 million people, with $78 \%$ living in the countryside. The agrarian sector of Khorezm accounts for $51 \%$ of the Gross Regional Product. The primary agricultural crop is cotton, followed by wheat and rice. The main water source for irrigation is the Amu Darya River, one of the two regional rivers that deliver water to the Aral Sea basin. Soils belonging to this zone are hard and loamy. The mean penetration of water is very low and the groundwater is very salty. 


\section{Stochastic frontier modelling}

The present study employed a stochastic frontier approach originally proposed by Aigner et al. (1977):

$$
y_{k}=f\left(x_{k, i} ; \beta_{i}\right) \exp \left(v_{k}-u_{k}\right)
$$

where: $y_{k}$ is the production quantity of the $k^{\text {th }}$ sample farm, $f($.$) characterizes a chosen$ functional form, and $x_{k, i}$ and $\beta_{i}$ are vector of inputs and their associated parameters, respectively. The model is stochastic, because the traditional error term equals $v_{k}-u_{k} \cdot v_{k}$ is a random error and is independently and identically distributed $\left\{N\left(0, \sigma_{v}^{2}\right)\right\}$. It includes all errors that occur due to the model misspecification and other factors (e.g. random shocks) that are beyond the farmers' control. $u_{k}$ is the asymmetric and non-negative error term which captures failures in resource utilization. This inefficiency indicator is independent, not only from $v_{k}$, but also from $y_{k}$ and $x_{k, i}$ used in the SFM. This assumption is necessary to avoid an endogeneity problem.

Given the input vector $x_{k}$, the $k^{\text {th }}$ farm's TE (i.e. more efficient use of inputs) is equal to the ratio of the $k^{\text {th }}$ farm's observed production, in relation to the production defined by the frontier:

$$
T E_{k}=\frac{F(x ; \beta) e^{\left(v_{k}-u_{k}\right)}}{F(x ; \beta) e^{\left(-u_{k}\right)}}=\exp \left(-u_{k}\right)
$$

The TE score is between zero and one. A farm is fully efficient when it equals one and fully inefficient if its value is zero.

The study aims to establish a theoretically consistent SFM, which requires meeting the essential microeconomic assumptions, including the monotonicity and curvature properties (Lau 1978). As Sauer (2006) and Henningsen and Henning (2009) stated, it is not possible to integrate these properties in the black box frontier tools introduced in the literature. Therefore, many studies have not taken these assumptions into account in terms of econometric modelling. Henningsen and Henning (2009) underlined that it is sufficient for the model to satisfy the monotonicity property, because in frontier models, farmers maximize their output, not their profits. Henningsen and Henning proposed a three-stage approach and showed how the monotonicity restriction can be applied in the frontier context.

The first stage involves the simultaneous estimation of Eqs. (3) and (4), as proposed by Battese and Coelli (1995). This study uses a translog functional form, which has independent variables that are at least equal to $1 / 2(n+2)(n+1)$ and fulfil the secondorder flexibility condition (Diewert 1974):

$$
\ln { }_{y k}=\beta_{0}+\sum_{i=1}^{n} \beta_{i} \ln x k, i+\frac{1}{2} \sum_{i=1}^{n} \sum_{j=1}^{n} \beta_{i, j} \ln _{x k, i} \ln x k, j+v_{k}-u_{k}
$$

as well as the theorem by Young that entails the symmetry of all Hessians $\left(\beta_{i j}=\beta_{j i}\right)$.

$$
u_{k}=\delta_{0}+\sum_{m} \delta_{m} Z_{k, m}+\varphi_{k}
$$

where: $u_{k}$ denotes the mean technical inefficiency obtained from Eq. (3). $Z_{k, m}$ describes the explanatory attributes and $\varphi_{k}$ is the non-negative random error represented by the 
truncation of the normal distribution with a zero mean and variance, $\sigma_{u}^{2}$. $\delta_{0}$ and $\delta_{m}$ are the inefficiency parameters to be estimated.

The monotonicity restriction is imposed in the second stage. This stage consists of solving a quadratic optimization model by imposing monotonicity on parameters via the asymptotically equivalent minimum distance estimator, together with the parameters of the production frontier, $\hat{\beta}$, and their covariance matrix, $\hat{\Omega}_{\beta}$, which are extracted from the first step:

$$
\hat{\beta}^{0}=\arg \min \left\{\left(\hat{\beta}^{0}-\hat{\beta}\right) \Omega_{\beta}^{-1}\left(\hat{\beta}^{0}-\hat{\beta}\right): f_{i}\left(x, \hat{\beta}^{0}\right) \geq 0 \forall i, x\right\}
$$

Here, $\hat{\beta}^{0}$ describes the model's restricted parameters, while $f_{i}\left(x, \hat{\beta}^{0}\right) \geq 0 \forall i, x$ is the monotonicity restriction imposed on the model. The third stage integrates these parameters to Eq. (6) and simultaneously estimates it with Eq. (7):

$$
\begin{aligned}
& \ln { }_{y k}=\omega_{0}+\omega_{1} \ln Y+v^{0}{ }_{k}-u^{0}{ }_{k} \\
& u_{k}=\delta_{0}{ }^{0}+\sum_{m} \delta^{0}{ }_{m} Z_{k m}+\gamma^{0}{ }_{k}
\end{aligned}
$$

Here, $Y$ equals $f\left(x, \hat{\beta}^{0}\right)$, which is acquired from Eq. (5); $\omega_{0}$ and $\omega_{1}$ are the adjustment parameters. One drawback of this approach is that it does not involve the determination of the standard errors for the restricted parameters (Tiedemann and Latacz-Lohmann 2012). On the other hand, it is rather straightforward in comparison to the Bayesian approaches, which involve complex algorithms that have some convergence problems.

\section{Modelling the farmer education and efficiency relationship}

One of the objectives of the study is to closely examine how the knowledge indicators would affect the TE of farmers. While these indicators could be included in the threestage model, the analysis does not offer the flexibility for modelling data with heterogeneous conditional distributions. Moreover, some of the knowledge indicators are highly correlated with other explanatory factors that lead to biased results.

To conduct the analysis, the research proposes employing a quantile regression (Koenker and Basset 1978, 1982) to estimate the impact of the knowledge effects at the lower quantile $\left(25^{\text {th }}\right.$ percentile), the medium quantile $\left(50^{\text {th }}\right.$ percentile) and the upper quantile $\left(75^{\text {th }}\right.$ percentile). A quantile regression models the relationship between the efficiency and knowledge indicators using a conditional quantile, evaluating the specific impact of these indicators on different groups of farms clustered on their level of efficiency. A running hypothesis is that the impact of knowledge indicators on the cotton farm TE will vary, depending on how far each farm is from the production frontier. This model can mathematically be expressed as follows (Buchinsky 1994, 1998):

$$
\begin{aligned}
& T E_{k}=\varsigma_{k} \beta_{\theta}+\mu_{\theta k} \\
& Q_{\theta}\left(T E_{k} \mid \varsigma\right)=\varsigma_{k} \beta_{\theta} \text { and } Q_{\theta}\left(\mu_{k} \mid \varsigma\right)=0
\end{aligned}
$$


where: $\beta_{\theta}$ and $\varsigma_{k}$ are $K^{*} 1$ vectors; $\varsigma$ is a vector of covariates; $Q_{\theta}\left(T E_{k} \mid \varsigma\right)$ is the $\theta$ th conditional quantile of TE given $\varsigma$, and TE is the $\mathrm{N}^{* 1} 1$ vector, which is obtained from the three stage model.

$\beta_{\theta}$ is obtained from the following expression:

$$
\operatorname{minimize} \sum_{k}\left|T E_{\theta k}-\sum_{l} \beta_{\theta l} \varsigma_{k l}\right|
$$

where: $T E_{\theta k}$ is the TE of farm $k$ at quantile $\theta(\mathrm{k}=1, \mathrm{n}) ; \varsigma_{k l}$ is the covariate $l$ for farmer $k$ and $\beta_{\theta l}$ is the impact of covariate $l$ on TE at quantile $\theta$.

The study considered two types of knowledge indicators, as discussed in ManevskaTasevska (2013): formal (e.g. years of schooling, educational background) and nonformal (e.g. participation in seminars) knowledge. It also includes an agricultural experience of farmer. In addition, the formal education variable was interacted with farm size and off-farm work variables to better depict the managerial and coordination capacity of the farming household.

\section{Data collection and sampling procedure}

The study used primary data obtained from a well-structured farm survey that was conducted between August and December of 2008. The survey used a quantitative and qualitative questionnaire to interview randomly selected cotton farmers, asking them to recall input-output data related to the cotton-growing season of 2007-2008. The study pre-tested the questionnaire by interviewing 20 randomly selected farmers in the Khonka district of the Khorezm province. This practice presented a clearer picture of the prospective problems that might arise during the interview for both the enumerators and the respondents. Enumerators with good knowledge of the study areas and the agricultural activities administered the farm survey. Individuals with effective communication skills were chosen and trained for a week to clarify the structure of the questionnaire and on what they should focus on during the interview. The study selected survey respondents using the multistage sampling technique. The first step comprised a purposeful selection of districts to capture an adequate representation of the province. For the analysis, eight out of ten districts were selected. The second step involved randomly selecting two to three villages (depending on the number of farmers) within the chosen districts. The study conducted the survey in 23 villages. In the third step, cotton farmers were randomly selected from each chosen village. The final analysis, after adjusting for missing cases and outliers, covered 298 cotton farms (for detailed explanations see Karimov 2012).

\section{Results and discussion}

\section{Description of the variables}

Table 1 presents the descriptive statistics of cotton yields, inputs, and the explanatory variables used in the analysis. Output is the harvested amount of cotton and is measured in tons. The study used a preliminary production model with five conventional inputs: cotton land area $(\times 1)$, labour $(\times 2)$, nitrogen fertilizer $(\times 3)$, diesel fuel $(\times 4)$, and seeds $(\times 5)$. The seed input variable was dropped from the final model, because of similar seeding rates (Hossain 1990; Alene and Hassan 2003). The land input variable also caused a problem with the model, as it was highly correlated with the other variables. 
Table 1 Descriptive statistics

\begin{tabular}{|c|c|c|c|c|c|}
\hline & \multirow[t]{2}{*}{ Units } & \multicolumn{4}{|c|}{ Khorezm ( $n=298$ observations) } \\
\hline & & Mean & SD & Min & Min \\
\hline \multicolumn{6}{|l|}{ Output variable } \\
\hline Yield & tons ha ${ }^{-1}$ & 2.72 & 0.43 & 1.9 & 3.6 \\
\hline \multicolumn{6}{|l|}{ Production variables } \\
\hline Diesel & $\mathrm{kg} \mathrm{ha}^{-1}$ & 204.65 & 50.47 & 100 & 300 \\
\hline Labour & Person-days ha ${ }^{-1}$ & 66.95 & 28.89 & 30 & 153 \\
\hline Nitrogen & $\mathrm{kg} \mathrm{ha}^{-1}$ & 197.2 & 38.92 & 100 & 277 \\
\hline Seeds & $\mathrm{kg} \mathrm{ha}^{-1}$ & 64.55 & 5.85 & 55 & 87 \\
\hline Land & $\mathrm{kg} \mathrm{ha}^{-1}$ & 15.22 & 12.84 & 1 & 81.5 \\
\hline \multicolumn{6}{|l|}{ Farm characteristics } \\
\hline Farm size (Fsize) & ha & 19.48 & 13.69 & 4.4 & 92.1 \\
\hline Bonitet score (Bscore) & Index (1-100) & 55.71 & 11.10 & 30 & 85 \\
\hline Obsolete Drainage (Drain) & Dummy & 0.51 & 0.50 & 0 & 1 \\
\hline Crop diversification index ${ }^{\mathrm{a}}$ (Div) & Index $(0 \leq)$ & 0.28 & 0.33 & 0 & 1.54 \\
\hline \multicolumn{6}{|c|}{ Socio-demographic and institutional characteristics } \\
\hline Participation in off-farm work (Offwork) & Dummy & 0.44 & 0.50 & 0 & 1 \\
\hline Dependency ratio ${ }^{\mathrm{b}}$ (Dratio) & Ratio & 1.00 & 1.12 & 0.1 & 8 \\
\hline Access to Credit (Acredit) & Dummy & 0.42 & 0.49 & 0 & 1 \\
\hline Satisfaction with WUA services (Wua) & Dummy & 0.39 & 0.49 & 0 & 1 \\
\hline \multicolumn{6}{|l|}{ Knowledge indicators } \\
\hline Agricultural experience (agexp) & Years & 14.54 & 7.81 & 3 & 38 \\
\hline Graduated from university (educ1) & Dummy & 0.30 & 0.46 & 0 & 1 \\
\hline Graduated from college (educ2) & Dummy & 0.46 & 0.50 & 0 & 1 \\
\hline Finished only high school (educ3) & Dummy & 0.24 & 0.43 & 0 & 1 \\
\hline Educational background (Edb) & Dummy & 0.49 & 0.50 & 0 & 1 \\
\hline Seminar participation (Seminar) & Frequency & 4.55 & 1.30 & 2 & 9 \\
\hline \multicolumn{6}{|l|}{ Agronomic practices } \\
\hline Water availability (Wavail) & Dummy & 0.45 & 0.50 & 0 & 1 \\
\hline Weeding frequency (Weedfreq) & Frequency & 5.73 & 1.55 & 2 & 10 \\
\hline Manure application (Manur) & Dummy & 0.47 & 0.50 & 0 & 1 \\
\hline
\end{tabular}

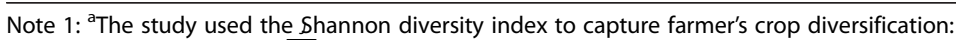

Shannon diversity index $=\sum_{i=1}\left(P_{i} * \ln P_{i}\right) \quad(11)$.

$J$ stands for the number of crops. The term $P_{i}$ is the proportion of the area used for a particular crop. In is the natural logarithm. It is zero if farmer grows only one crop.

Note 2: ${ }^{b}$ Ratio of family dependents aged below 15 and above 60 compared to the number of family adults who are of working age.

The study normalized the dataset by dividing the inputs and outputs by the land input variable, resulting in dropping it from the regression model. The labour input variable is in person-days. One working day is equal to eight hours. The final model includes only pre-harvest labour (family and hired labour) because of the inconsistency in the collected primary data related to the harvest and post-harvest period. Ekayanake (1987) also argued that labour activities in these periods influence the yield on a small scale and do not affect the production frontier. The study calculated nitrogen fertilizer $(\mathrm{kg})$ from the acquired fertilizer application data, considering the share of nitrogen in the content of each fertilizer. The survey revealed that the farmers used nine types of 
fertilizers for cotton production. Diesel fuel is included as a proxy variable for machinery services and is measured in $\mathrm{kg}$. The explanatory variables are divided into four groups: farm (household) aspects, socio-demographic and institutional characteristics, knowledge indicators and agronomic practices. Several interesting points can be observed from the descriptive analysis. Farms in the sample have a mean bonitet score of 55 , which indicates that the average quality of the lands used by the farmers is relatively low. Here, the bonitet is a soil potential productivity value measured on a scale of 1 to 100. The calculation of bonitet levels were developed during the Soviet period for the calculation of state quota levels (Noble et al. 2005). The larger the index value, the more fertile is the land, and hence, a higher the quota. The average farm size is 19.5 ha and, on average, farmers have 15 years of agricultural experience. Only about half of the farmers reported that they have received a sufficient amount of water and applied the recommended amount of manure to their cotton fields. On average, 39\% of them are satisfied with WUA (Retitled to the Water Consumers Association [WCA] in 2009) services. It should be noted that the Ministry of Agriculture and Water Resources (MAWR) is the primary body that manages irrigated agriculture in the country. One of its key actors is the WUA, an intermediary between the MAWR and the farmers. In 2008, there were about 112 WUAs in the Khorezm province. Although their main responsibility is to manage the delivery of water for all agricultural products, cotton and grain fields are a priority. Farmers formally cooperate on water management matters under the supervision of the WUA (Van Assche and Hornidge 2012). Interestingly, 51\% of the farmers reported that they have poor drainage systems, which also stresses potential water loss during the vegetation period (Bekchanov et al. 2012). On average, $42 \%$ of farmers expressed easier access to credit and $44 \%$ participated in off-farm activities. Since a basic high school level education is compulsory in Uzbekistan, all surveyed farmers had finished their basic education. Upon the completion of high school, people have a choice to go to a university or a college. Universities produce high-level specialists, while colleges produce middle-level professionals. Farmers in the sample illustrated that $30 \%$ of them had graduated from universities and $46 \%$ of them had graduated from colleges (vocational education). $24 \%$ of farmers in the sample did not continue their studies after obtaining basic education. Interestingly, half of the sampled farmers who studied in universities and colleges majored in agriculturally related subjects (e.g. agronomy, biology, irrigation engineering).

\section{Production frontier analysis}

The study used the $R$ package 'frontier' (Coelli and Henningsen 2009) to estimate the traditional (unrestricted) and restricted SFM. The package 'quadprog' (Turlach and Weingessel 2011) was used to calculate the minimum distance estimation. The results of each model at each stage appear in Table 2. As seen from the first stage analysis, the input variables, including nitrogen fertilizer, labour and diesel fuel, demonstrate a significant and an expected positive relationship with cotton yield. Some of the interaction terms are significant, showing a sign of non-linearity in the structure of production. A theoretical consistency is met by imposing monotonicity. Due to this restriction, a small change is observed in the model coefficients (the column labelled 'difference' [Diff.]) estimated in the first and second stages. The change is less than one times the standard 
Table 2 Comparison of coefficients obtained from three stages

\begin{tabular}{|c|c|c|c|c|c|c|c|c|}
\hline & & $1^{\text {st }}$ Step & & & $2^{\text {nd }}$ Step & & & $3^{\text {rd }}$ Step \\
\hline & & MLE Coeff. & & $\mathrm{SE}$ & MDE Coeff. & Diff. & Diff/SE & Adj. Coeff. \\
\hline Constant & $\beta_{0}$ & 2.443 & 0.306 & $* * *$ & 2.257 & -0.186 & -0.609 & 2.246 \\
\hline Ln (Diesel) & $\beta_{1}$ & 0.565 & 0.216 & $* * *$ & 0.527 & -0.038 & -0.127 & 0.522 \\
\hline Ln (Labour) & $\beta_{2}$ & 0.281 & 0.109 & $* *$ & 0.192 & -0.089 & -0.295 & 0.190 \\
\hline Ln (Nitrogen) & $\beta_{3}$ & 0.834 & 0.290 & $* * *$ & 0.606 & -0.228 & -0.753 & 0.600 \\
\hline $\operatorname{Ln}($ Diesel)* $\operatorname{Ln}($ Diesel) & $\beta_{11}$ & 0.157 & 0.104 & NS & 0.138 & -0.018 & -0.060 & 0.137 \\
\hline $\operatorname{Ln}($ Diesel)* Ln(Labour) & $\beta_{12}$ & 0.056 & 0.034 & * & 0.035 & -0.021 & -0.070 & 0.034 \\
\hline $\operatorname{Ln}($ Diesel)* $\operatorname{Ln}($ Nitrogen) & $\beta_{13}$ & 0.125 & 0.066 & * & 0.107 & -0.017 & -0.057 & 0.106 \\
\hline $\operatorname{Ln}($ Labour)* $\operatorname{Ln}($ Labour $)$ & $\beta_{22}$ & -0.089 & 0.048 & $*$ & -0.055 & 0.034 & 0.111 & -0.054 \\
\hline Ln(Labour) ${ }^{*}$ Ln(Nitrogen) & $\beta_{23}$ & 0.038 & 0.046 & NS & 0.020 & -0.018 & -0.059 & 0.020 \\
\hline $\operatorname{Ln}($ Nitrogen)* $\operatorname{Ln}($ Nitrogen) & $\beta_{33}$ & 0.300 & 0.171 & $*$ & 0.173 & -0.126 & -0.417 & 0.172 \\
\hline
\end{tabular}

Note:*******indicates significance at the 1,5 and $10 \%$ levels, respectively.

error of the first-step estimation (see the column 'difference/SE' [Diff/SE]). The final estimates ('adjusted coefficients' [Adj. Coeff.]) demonstrate the restricted coefficients after modifying the production frontier with the $\omega_{0}$ and $\omega_{1}$ coefficients. The production elasticity relating to labour is equal to 0.07 , which is much lower than the elasticities relating to nitrogen and diesel. The nitrogen and diesel production elasticities have similar values ranging between 0.15 and 0.18 .

The study tests three hypotheses with regard to the specification of the model using a likelihood ratio test. The first hypothesis is the choice of the Cobb-Douglas (C-D) versus the translog functional form. The study rejects the C-D as the preferred functional form (the null hypothesis), which suggests that the translog functional form is the appropriate one. The second hypothesis is a technical inefficiency test, with the null hypothesis being no inefficiency effect. The study rejects this hypothesis as well, which implies that the joint effect of the explanatory factors significantly contribute to TE. The third hypothesis is the restricted versus unrestricted model. The study fails to reject that the restricted frontier model is the preferred model (A likelihood ratio test and Wald test returned $p$-values of 0.68 and 0.78 , respectively). This implies that monotonicity is an important property, which needs to be taken into account in frontier modelling.

As can be seen in Table 3, the variance parameter (SigmaSq) is positive and statistically significant at the $1 \%$ level. This illustrates the goodness of the composite error's distributional assumptions. Gamma $(\gamma)$ is equal to 0.98 and significant at $1 \%$, which indicates that the technical inefficiency effect describes a considerable fraction of the total variation in the data. The final restricted model entirely satisfies the monotonicity condition for all observations and variables and is quasiconcave at $93.3 \%$ of the observations. The imposition of the monotonicity improved the significance of some of the variables in the final model (Table 3). The off-farm work variable (offwork) became significant at $10 \%$ and for the three other variables' (Acredit, Wua and Drainage) the significance level increased from $5 \%$ to $1 \%$. The intercept is not significant and the scaling coefficient is virtually one, which indicates the robustness of the model. Hence, the imposition of the monotonicity constraint slightly affected the distribution of the TE (Figure 1) by moving the average TE from 0.84 to 0.86 . As the results from the TE distribution from 
Table 3 Results from unrestricted and restricted models

\begin{tabular}{|c|c|c|c|c|c|c|}
\hline \multirow{3}{*}{ Final Stage } & \multicolumn{3}{|c|}{ Initial estimates } & \multicolumn{3}{|c|}{ Final estimates } \\
\hline & \multicolumn{2}{|l|}{ Coefficient } & \multirow[t]{2}{*}{ SE } & \multicolumn{2}{|l|}{ Coefficient } & \multirow[t]{2}{*}{ SE } \\
\hline & & & & & & \\
\hline & & & & 0.011 & & 0.067 \\
\hline LcFitted & & & & 0.99 & $* * *$ & 0.057 \\
\hline \multicolumn{7}{|c|}{ Inefficiency Effects Model } \\
\hline Constant & 0.486 & $* * *$ & 0.306 & 0.488 & $* * *$ & 0.043 \\
\hline Bscore & -0.001 & NS & 0.216 & -0.001 & NS & 0.001 \\
\hline Fsize & -0.002 & $* * *$ & 0.109 & -0.002 & $* * *$ & 0.001 \\
\hline Wavail & -0.072 & $* * *$ & 0.29 & -0.072 & $* * *$ & 0.013 \\
\hline Weedfreq & -0.024 & $* * *$ & 0.104 & -0.024 & $* * *$ & 0.005 \\
\hline Div & -0.011 & NS & 0.034 & -0.013 & NS & 0.022 \\
\hline Offwork & 0.024 & NS & 0.066 & 0.023 & * & 0.013 \\
\hline $\mathrm{Edb}$ & -0.061 & $* * *$ & 0.048 & -0.062 & $* * *$ & 0.019 \\
\hline Manur & -0.043 & $* *$ & 0.046 & -0.044 & $* *$ & 0.019 \\
\hline Dratio & 0.003 & NS & 0.171 & 0.003 & NS & 0.008 \\
\hline Acredit & -0.058 & $* *$ & 0.053 & -0.06 & $* * *$ & 0.014 \\
\hline Wua & -0.067 & $* *$ & 0.001 & -0.069 & $* * *$ & 0.015 \\
\hline Drain & 0.043 & $* *$ & 0.001 & 0.045 & $* * *$ & 0.013 \\
\hline \multicolumn{7}{|c|}{ Efficiency Diagnostics } \\
\hline SigmaSq & 0.008 & $* * *$ & 0.02 & 0.008 & $* * *$ & 0.001 \\
\hline Gamma & 0.989 & $* * *$ & 0.005 & 0.982 & $* * *$ & 0.014 \\
\hline
\end{tabular}

Note:*******indicates significance at the 1,5 and $10 \%$ levels, respectively.

the unrestricted and restricted models show, $37 \%$ of the farms fall below the 0.80 efficiency score. Because the highest TE is achieved at a score of 1.0, the model results indicate that there is still room for efficiency improvements with the farmers' existing technologies. Hence, the findings suggest that farms could increase their production without purchasing more inputs under the given agricultural set.
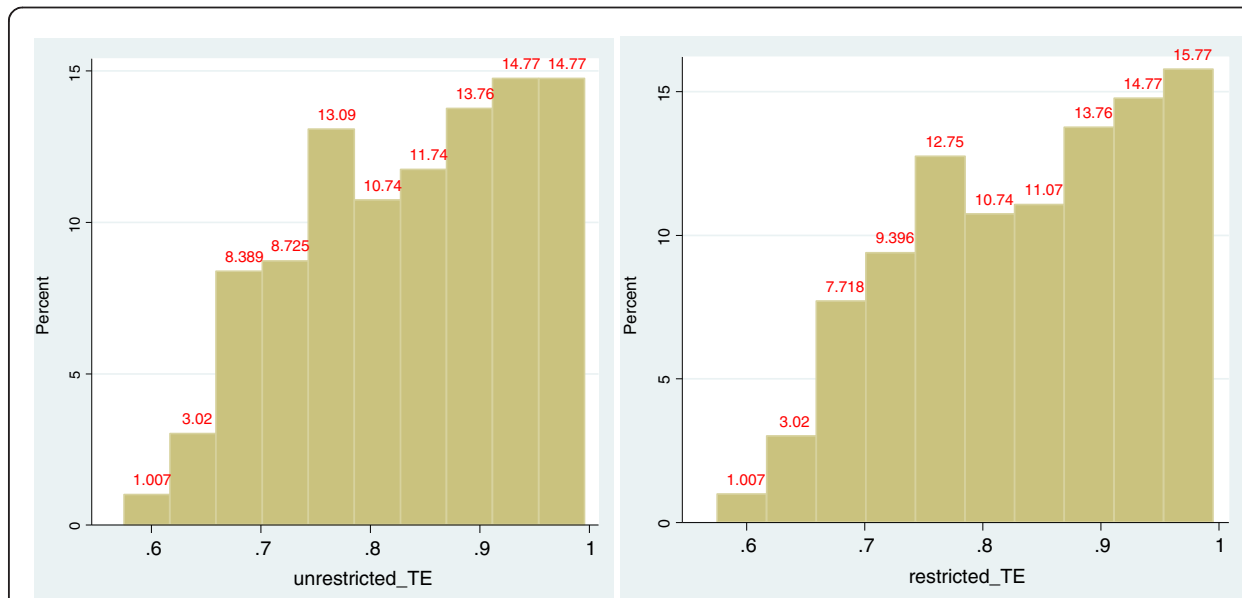

Figure 1 Predicted technical efficiency distribution. 


\section{Inefficiency effects analysis}

The inefficiency effects model (Eq.7) included 12 variables (Table 3). While the model uses technical inefficiency as a dependent variable, for convenience, the study used TE in explaining the outcomes. As a result, the sign of the explanatory variables are changed in the discussion. The farm size variable (fsize, measured in total ha of the farm) has a positive and significant relationship with TE. This illustrates that the scale of operations matters in resource utilization. In general, large farmlands have been leased to financially stable and experienced farmers who had worked in state farms and cooperatives (shirkats-in Uzbek). These farms established good contacts with the local administration and the input distribution points (Noble et al. 2005) and gained the capacity to invest in agricultural technologies.

The results also illustrate that the water availability dummy (Wavail) has a positive and significant result with TE. This suggests that easier access to recommended irrigation water during the cotton season enables farmers to be more efficient. This helps agronomic activities to be performed on time and to obtain higher yields at the end of the season. However, this finding should be carefully interpreted, because tail end users may still not obtain the available water because of their naturally inconvenient location (Bekchanov et al. 2010). The study also included two other variables related to irrigation. One of the variables is the WUA dummy (Wua), used as an indicator to measure the level of farmers' satisfaction with WUA services. This variable is significant and positively correlated with TE. Another water related variable is the poor drainage dummy (Drain), used to obtain information regarding the condition of the drainage system adjacent to the field and its possible impact on TE. The analysis shows that those who have a poor drainage system illustrated lower TE levels in using inputs. A study by Tian and Wan (2000) had similar results. As Forkutsa (2006) mentioned, poor drainage is the result of failures in water management. When there is reduced access to irrigation water during the vegetation period, farmers attempt to block adjacent drains, which helps to preserve a high soil moisture (Tischbein et al. 2012). This, however, leads to a malfunctioning in the drainage systems, an overuse of labour, and a delay in agronomic practices.

The findings show that the increased number of weeding activities (Weedfreq) positively affects the TE of farms. Djalalov and Gemma (2006) stressed that land salinization and weeding are major problems which could be, partly, the result of poor agronomic practices (e.g. inadequate crop rotations) and low incentives for conserving water. Applying chemicals is not always possible, because of the high costs involved and because the application of chemicals decreases the quality of the cotton. Manual weeding is usually done by farm family members, whereas in larger cotton areas, hired labour is used.

The off-farm work dummy (Offwork) has a negative sign on TE. Those who have engaged in off-farm activities achieved lower efficiencies in cotton production. It is not a surprising result, because farmers have to share their time between farming and other offfarm activities. Djalalov (2006) indicated that farming is not a single source of income for many rural farmers. Hence, although farmers can invest their additional income in cotton production, time spent on off-farm work might have an efficiency reducing effect.

The manure application dummy (Manur) is also significant. The results suggest that farmers who applied the recommended norms of organic manure achieved higher efficiencies. Obtaining organic manure is very difficult during the agricultural season, as there is shortage of supply in the livestock market (informal) and the price of manure 
is high. Hence, there is a clear need for efficiently managing the crop residues and increasing the amount of animal waste produced on the farm (Blanchard et al. 2013).

The access to credit dummy (Acredit) is another very important indicator, which illustrates a positive impact on TE. A lack of cash during the cotton season originates from either the unavailability of agricultural credit (Djanibekov et al. 2012; Rudenko et al. 2012) or the difficulty in securing it (Djalalov 2006). The study finds that farmers who reported that they have easier access to credit displayed higher TE results. Access to additional finances enables farmers to hire additional labour and purchase fertilizer from private sources. Bozoglu and Ceyhan (2007) found a similar result from an analysis of Turkish farmers.

\section{Quantile analysis: importance of knowledge indicators}

The results from the quantile regression are presented in Table 4 . This study finds that those farmers who have a university education (Educ1) are efficient in resource utilization at the $5 \%$ significance level in the $25^{\text {th }}$ and $50^{\text {th }}$ TE percentiles. However, this relationship is only significant at the $10 \%$ significance level in the $75^{\text {th }}$ TE percentile. This suggests that obtaining a higher education positively affects TE, but there is weak evidence for its contribution to higher TE levels. This stresses the importance of specialized knowledge required for better farming. To support this argument, the study also associated farm efficiency with agriculture related education $(E d b)$. The results show that the educational background of the farmer matters for efficiency improvements. The relationship between those who have received an agricultural education and efficiency are highly significant, but that the relationship has a concave form. This pattern advocates diminishing returns to agricultural education at the higher tail of TE distribution. A clear explanation is that farmers with an educational background in agriculture are able to use agronomic practices on time and in an effective and efficient manner. They know the specifics of farming and can adjust to different situations, depending on the available resources. Only a few studies used this variable in their analysis. One study was conducted by Manevska-Tasevska (2013), who does not find any significant relationship.

Interestingly, the study does not observe any significant connection between efficiency and those who have only received a compulsory basic education (Educ3). This illustrates that the influence of farmers' formal education on farm efficiency is dependent on the level of education received. This finding is contrary to the one obtained by Asadullah and

Table 4 Results from Quantile regression

\begin{tabular}{|c|c|c|c|c|c|c|c|c|c|}
\hline \multirow[b]{3}{*}{ Seminar } & \multicolumn{3}{|l|}{0.25} & \multicolumn{3}{|l|}{0.5} & \multicolumn{3}{|l|}{0.75} \\
\hline & \multirow{2}{*}{$\frac{\text { Coef. }}{0.011}$} & \multicolumn{2}{|c|}{ Standard error } & \multirow{2}{*}{$\frac{\text { Coef. }}{0.026}$} & \multicolumn{2}{|c|}{ Standard error } & \multirow{2}{*}{$\begin{array}{l}\text { Coef. } \\
0.018\end{array}$} & \multicolumn{2}{|c|}{ Standard error } \\
\hline & & 0.005 & * & & 0.005 & $* * *$ & & 0.006 & $* * *$ \\
\hline Agexp & 0.002 & 0.001 & $* *$ & 0.001 & 0.001 & NS & 0.001 & 0.001 & NS \\
\hline Educ1 & 0.061 & 0.028 & $* *$ & 0.058 & 0.023 & ** & 0.059 & 0.032 & $*$ \\
\hline Educ3 & 0.024 & 0.029 & NS & 0.014 & 0.024 & NS & 0.038 & 0.032 & NS \\
\hline Edb & 0.063 & 0.017 & $* * *$ & 0.070 & 0.015 & $* * *$ & 0.061 & 0.021 & $* * *$ \\
\hline Ed2*Fsize & 0.002 & 0.001 & $* *$ & 0.001 & 0.001 & * & 0.002 & 0.001 & $*$ \\
\hline Offwork*educ1 & -0.087 & 0.025 & $* * *$ & -0.078 & 0.022 & $* * *$ & -0.082 & 0.031 & $* * *$ \\
\hline Offwork*educ2 & -0.046 & 0.022 & $* *$ & -0.041 & 0.018 & $* *$ & -0.049 & 0.026 & * \\
\hline _cons & 0.644 & 0.035 & $* * *$ & 0.660 & 0.031 & $* * *$ & 0.757 & 0.042 & $* * *$ \\
\hline
\end{tabular}

Note:*******indicates significance at the 1,5 and $10 \%$ levels, respectively. 
Rahman (2009), who stressed that primary and secondary education are more relevant in farming than higher education. Pritchett (2001) concludes that, in some nations, schooling is effective in transferring knowledge, whereas it is insignificant in others and shapes no skills. Reimers and Klasen (2013) stressed that the education effect is smaller for the poorest nations, whereas Manevska-Tasevska (2013) could not find any significant results in the case of grape growing farms in Macedonia. Kalaitzandonakes and Dunn (1995) argued that differing results could be attributable to difficulties in measuring the education variable.

The study used the interaction term between university ( $E d u c 1)$ and college education (Educ2) with off farm-work (Offwork) and found statistically significant results, regardless of the different quantile groups. The effect is strongest in the case of those who have a university education. This indicates that highly educated farmers do not have the capacity to handle on and off-farm activities, which badly reflects on resource utilization. This also implies that better time allocation and a physical coordination of daily activities are important. The results of this study revealed the importance of the knowledge gained from non-formal education (Seminar), as this was found to have a statistically significant positive influence on efficiency in all of the quantiles and have a concave shape. Manevska-Tasevska (2013) also found a positive relationship between non-formal education and TE. This shows the need for agricultural training programs that help farmers to upgrade their knowledge and obtain up-to-date information about new technologies applied in agricultural production. In this regard, Kazbekov and Qureshi (2011) urged for the need to establish formal extension services to assist farmers in achieving higher productivity. Karimov (2013a) stressed that these organizations will support farmers to adopt technical innovations with a possible impact on agricultural land and labour productivity.

The agricultural experience (Agexp) of the farmer is only significant at the $25^{\text {th }} \mathrm{TE}$ percentile and statistically not significant in the other two quantiles. This suggests that farming experience does not contribute to achieving higher efficiency values. While cotton is grown for many years and farmers gained extensive experience in its production, the study illustrates that acquired knowledge is not enough to increase cotton yields to the expected levels. Manevska-Tasevska (2013) found a negative relationship here and explained it by the fact that more experienced farmers were more resistant to new technologies and practices. The interaction term between college education (Educ2) and farm size (Fsize) has been introduced to explore the farmer's managerial ability to handle work at large scale farms. It is significant at the $5 \%$ level in the $25^{\text {th }} \mathrm{TE}$ quantile and significant at the $10 \%$ level in the $50^{\text {th }}$ and $75^{\text {th }} \mathrm{TE}$ quantiles; it also displayed a $\mathrm{U}$ shape across the quantiles. This shows that obtaining a formal education is not sufficient enough to achieve higher efficiency, especially in the large-scale farmlands, and hence, achieving higher efficiency requires additional training and managerial skills from farmers.

\section{Conclusions}

Cotton production in Uzbekistan has a long agricultural history and farmers are experienced in producing it. Because of land reforms which occurred after achieving independence in 1991 and under threats of increasing water scarcity and a reduction in the fertility of farmlands, the efficient resource use has become an important issue in public discussions and a worthy research topic. 
The present research applied recent methodological developments and evaluated the efficiency of cotton farms in the Khorezm province of Uzbekistan. Because few studies currently exist in the context of CA (Karimov 2013b), this study filled a gap in the literature by providing a theoretically consistent model and applying it to an interesting case with a complex socio-economic environment. It underlined the significance of the monotonicity and quasiconcavity violations, which can cause biased efficiency results. As the model results illustrate, the average farmer in the Khorezm sample could increase output levels if production factors are efficiently used, so as to obtain higher margins from the sale of cotton to the state.

The study further reveals some factors that significantly influence farmers' resource use abilities. One of the significant factors associated with efficiency is the off-farm work variable. Because cotton production requires full concentration all year, farmers who engage in off-farm work achieved a lower efficiency. This is especially true for those who have university and college educations. The study also finds that easier access to agricultural credit has a positive impact on resource utilization. Notably, providing privileged credit in the context of the state quota system helps farmers to purchase the required inputs and use them on time, thus avoiding possible crop losses. The findings also show that big farms are more efficient in resource use. Thus, a state's decision to consolidate farms further is plausible. The model's results further point to some other variables that improve TE, including access to adequate irrigation, frequency of weeding, application of organic manure, better WUA services, and renovated drainage systems. The study also confirmed that farmers' knowledge attributes have the potential to impact the farmers' resource use pattern. It is also interesting to note that formal education (university degree and educational background in agriculture) and informal education (participation in seminars) are associated with efficiency-improving results. Interestingly, the results indicate that a basic education is not sufficient to achieve higher efficiency in cotton production. In this regard, a state policy to establish colleges in rural and remote areas is well placed under the current situation and brings about significant returns in the near future.

At the same time, the farmer's managerial ability is not enough to increase the TE on large farms, which requires obtaining organizational skills and knowledge. Agricultural experience is significant only in the lower tail of the TE percentile, which suggests that cotton farmers need agricultural training, despite being experienced in farming. Kienzler et al. (2011) also stressed the important role of agricultural training in crop production. In this sense, the role of a non-formal education is substantial, as it was positively related to TE. Vakhabov et al. (2006) emphasized the prominence of scientific research institutes, both at the national and local levels, to better transfer new technologies and share innovative methods. Djanibekov et al. (2010) emphasized that agricultural advisory services have several challenges in transferring knowledge to farmers, possibly because of lack of sustainable funds to support their functioning. This requires finding and supporting innovative ways of financing extension and advisory services. 


\section{Acknowledgements}

The research was conducted with the support of the ZEF/UNESCO Khorezm project "Economic and Ecological Restructuring of Land and Water Use in the Region Khorezm (Uzbekistan): A Pilot Project in Development Research" funded by the Federal Ministry of Education and Research (BMBF), Germany (Project Number 339970D) and implemented by the Center for Development Research/Zentrum für Entwicklungsforschung (ZEF), University of Bonn, Germany.

Received: 13 April 2013 Accepted: 14 April 2014

Published online: 31 May 2014

\section{References}

Aigner D, Lovell C, Schmidt P (1977) Formulation and estimation of stochastic frontier production function models. J Econ 6:21-37. doi:dx.doi.org/10.1016/0304-4076 (77)90052-5

Alene AD, Hassan RM (2003) The determinants of farm-level technical efficiency among adopters of improved maize production technology in western Ethiopia. Agrekon 42:1-14. doi:dx.doi.org/10.1080/03031853.2003.9523606

Aminova M, Abdullayev I (2009) Water management in a state - centered environment: water governance analysis of Uzbekistan. Sustainability 1:1240-1265. doi:dx.doi.org/10.3390/su1041240

Asadullah MN, Rahman S (2009) Farm productivity and efficiency in rural Bangladesh: the role of education revisited. Appl Econ 41:17-33. doi:dx.doi.org/10.1080/00036840601019125

Asian Development Bank (2008) Uzbekistan: Implementation and Monitoring of Policy Reforms in the Agriculture Sector, Technical Assistance Consultant's Report, prepared by ScanAgri Sweden AB for the Asian Development Bank., http://www2.adb.org/Documents/Produced-Under-TA/37536/37536-01-UZB-DPTA.pdf. Accessed 25 December 2012

Awotide BA, Karimov A, Diagne A, Nakelse T (2013) The impact of seed vouchers on poverty reduction among smallholder rice farmers in Nigeria. Agr Econ 44:647-658. doi:dx.doi.org/10.1111/agec.12079

Battese GE, Coelli TJ (1995) A model for technical inefficiency effects in a stochastic frontier production function for panel data. Empir Econ 20:325-332. doi:dx.doi.org/10.1007/BF01205442

Bekchanov M, Karimov A, Lamers J (2010) Impact of water availability on land and water productivity: a temporal and spatial analysis of the case study region Khorezm, Uzbekistan. Water 2:668-684. doi:dx.doi.org/10.3390/w2030668

Bekchanov M, Lamers J, Karimov A, Müller M (2012) Estimation of spatial and temporal variability of crop water productivity with incomplete data. In: Martius C, Lamers J, Vlek PLG (eds) Cotton, Water, Salts and SoumsEconomic and Ecological Restructuring in Khorezm, Uzbekistan. Springer, Heidelberg, pp 329-344

Blanchard M, Vayssieres J, Dugué P, Vall E (2013) Local technical knowledge and efficiency of Organic fertilizer production in South Mali: Diversity of practices. Agroecology Sust Food Syst 37:672-699. doi:dx.doi.org/10.1080/ 21683565.2013.775687

Bozoglu M, Ceyhan V (2007) Measuring the technical efficiency and exploring the inefficiency determinants of vegetable farms in Samsun province, Turkey. Agric Syst 94:649-656. doi:dx.doi.org/10.1016/j.agsy.2007.01.007

Buchinsky M (1994) Changes in the US wage structure 1963-1987: application of quantile regression. Econometrica 62:405-458

Buchinsky M (1998) Recent advances in quantile regression models: a practical guideline for empirical research. J Hum Resour 33:88-126

Chirwa E (2007) Sources of technical efficiency among smallholder maize farmers in Southern Malawi. AERC Research Paper 172., http://www.ndr.mw:8080/xmlui/handle/123456789/324 Accessed 15 December 2012

Coelli T, Henningsen A (2009) Frontier package for stochastic frontier analysis in R., http://frontier.r-forge.r-project.org. Accessed 21 October 2012

Diewert WE (1974) Functional forms for revenue and factor requirements functions. Int Econ Rev 15:119-130

Djalalov S (2006) The Sustainable Development of Water Users Associations in Uzbekistan. In: Babu S, Djalalov S (eds) Policy Reforms and Agriculture Development in Central Asia. Springer, New York, pp 371-393

Djalalov S, Gemma M (2006) Impact of policy reforms on farm production in Uzbekistan. In: Babu S, Djalalov S (eds) Policy Reforms and Agriculture Development in Central Asia. Springer, New york, pp 239-255

Djanibekov N, Lamers J, Bobojonov I (2010) Land Consolidation for Increasing Cotton Production in Uzbekistan: Also Adequate for Triggering Rural Development? In: Labar K, Petrick M, Buchenrieder G (eds) Challenges of Education and Innovation for Agricultural Development: Proceedings of the Fourth Green Week Scientific Conference on the Agricultural and Food Sector in Central and Eastern Europe. IAMO, Halle (Saale)

Djanibekov N, Bobojonov I, Lamers J (2012) Farm reform in Uzbekistan. In: Martius C, Lamers J, Vlek P (eds) Cotton, Water, Salts and Soums - economic and ecological restructuring in Khorezm, Uzbekistan. Springer, Heidelberg, pp 95-112

Ekayanake S (1987) Location specificity, settler type and productive efficiency: a study of the Mahaweli project in Sri Lanka. The J Dev Stud 23:509-521. doi:dx.doi.org/10.1080/00220388708422046

Food and Agriculture Organization of United Nations (2003) Fertilizer use by crop in Uzbekistan., ftp://ftp.fao.org/agl/ agll/docs/fertuseuzbekistan.pdf Accessed 09 December 2011

Forkutsa I (2006) Modeling water and salt dynamics under irrigated cotton with shallow groundwater in the Khorezm region of Uzbekistan. Dissertation, Bonn University., http://www.zef.de/fileadmin/webfiles/downloads/ zefc_ecology_development/ecol_dev_37_text.pdf Accessed 13 March 2013

Guadagni M, Raiser M, Crole-Rees A, Khidirov D (2005) Cotton taxation in Uzbekistan: Oportunities for reform, Working paper No. 41. The World Bank, Tashkent, Uzbekistan, http://r0.unctad.org/infocomm/anglais/cotton/Doc/Uzbek_TAX.pdf Accessed 21 January 2012

Henningsen A, Henning CHC (2009) Imposing regional monotonicity on translog stochastic production frontiers with a simple three-step procedure. J Prod Anal 32:217-229. doi:dx.doi.org/10.1007/s11123-009-0142-x

Hossain A (1990) Real wage determination in Bangladesh agriculture: an econometric investigation. Appl Econ 22:1549-1565. doi:dx.doi.org/10.1080/00036849000000123

Kalaitzandonakes NG, Dunn EG (1995) Technical efficiency, managerial ability and farmer education in Guatemalan Corn production: a Latent variable analysis. Agr Res Econ Rev 24:36-46

Karimov A (2012) An economic efficiency analysis of crop producing farms in Uzbekistan: Explanatory factors and estimation techniques. Cuvillier Verlag, Gottingen 
Karimov A (2013a) Economic inefficiency and shadow prices of inputs: the case of vegetable growing farms in Uzbekistan. Procedia Econ Fin 5:403-412. doi:dx.doi.org/10.1016/52212-5671(13)00048-8

Karimov A (2013b) Productive efficiency of potato and melon growing farms in Uzbekistan: a two stage double bootrsap data envelopment analysis. Ağrı 3:503-515. doi:dx.doi.org/10.3390/agriculture3030503

Kazbekov J, Qureshi A (2011) Agricultural extension in Central Asia: Existing strategies and future needs. IWMI Working paper 145., http://wwww.iwmi.cgiar.org/Publications/Working_Papers/working/WOR145.pdf. Accessed 12 September 2013

Kienzler KM, Djanibekov N, Lamers J (2011) An agronomic, economic and behavioral analysis of N application to cotton and wheat in post-Soviet Uzbekistan. Agric Syst 104:411-418. doi:dx.doi.org/10.1016/j.agsy.2011.01.005

Koenker R, Bassett G Jr (1978) Regression quantiles. Econometrica 46:33-50

Koenker R, Bassett G (1982) Tests of Linear Hypotheses and I" 1 Estimation. Econometrica 50:1577-1583

Lau LJ (1978) Testing and imposing monotonicity, convexity and quasi-convexity constraints. In: Fuss M, Mc.Fadden D (eds) Production Economics: A dual approach to Theory and Applications, vol. I. North-Holland publishing co., Amsterdam

Liefert WM, Liefert O (2012) Russian agriculture during transition: performance, global impact, and outlook. Appl Econ Persp Pol 34:37-75. doi:dx.doi.org/10.1093/aepp/ppr046

Llewelyn RV, Williams JR (1996) Nonparametric analysis of technical, pure technical, and scale efficiencies for food crop production in East Java, Indonesia. Agr Econ 15:113-126. doi:dx.doi.org/10.1016/S0169-5150(96)01202-9

Manevska-Tasevska G (2013) Farmers' knowledge attributes contribute to attaining higher farm technical efficiency: a transition economy case. J Agr Ed Ext 19:7-19. doi:dx.doi.org/10.1080/1389224X.2012.746001

Mathijs E, Vranken L (2001) Human capital, gender and organisation in transition agriculture: measuring and explaining the technical efficiency of Bulgarian and Hungarian farms. Post-Communist Econ 13:171-187. doi:dx.doi.org/ $10.1080 / 14631370120052654$

Noble A, Hassan UI M, Kazbekov J (2005) "Bright Spots" in Uzbekistan, reversing land and water degradation while improving livelihoods. IWMI Research Report No.88., http://www.iwmi.cgiar.org/Publications/IWMI_Research_Reports/ PDF/pub088/RR88.pdf. Accessed 24 January 2009

Pritchett L (2001) Where has all the education gone? World Bank Econ Rev 15:367-391. doi:dx.doi.org/10.1093/wber/15.3.367

Reimers M, Klasen S (2013) Revisiting the role of education for agricultural productivity. Am J Agr Econ 95:131-152. doi:dx.doi.org/10.1093/ajae/aas118

Rudenko I (2008) Value Chains in Uzbekistan: The case of cotton, wheat and vegetable chains in Khorezm province and their potential for developing agricultural sector. Dissertation, University of Hannover, Hannover

Rudenko I, Nurmetov K, Lamers J (2012) State order and policy strategies in the cotton and wheat value chains. In: Martius C, Lamers J, Vlek P (eds) Cotton, Water. Salts and Soums - economic and ecological restructuring in Khorezm, Uzbekistan, Springer, Heidelberg, pp 371-388

Sauer J (2006) Economic theory and econometric practice: parametric efficiency analysis. Empir Econ 31:1061-1087. doi:dx.doi.org/10.1007/s00181-006-0068-3

Tashrifov Y (2005) The effects of market reform on cotton technical efficiency:The case of Tajikistan, Working paper No. 8, Australian National University., https://crawford.anu.edu.au/degrees/idec/working_papers/IDEC05-8.pdf Accessed 21 January 2012

Tian W. Wan GH (2000) Technical efficiency and its determinants in China's grain production. J Prod Anal 13:159-174. doi:dx.doi.org/10.1023/A:1007805015716

Tiedemann T, Latacz-Lohmann U (2012) Production risk and technical efficiency in organic and conventional agriculture - the case of arable farms in Germany. J Agr Econ 64:73-96. doi:dx.doi.org/10.1111/j.14779552.2012.00364.x

Tischbein B, Awan UK, Abdullaev I, Bobojonov I, Conrad C, Jabborov H, Forkutsa I, Ibrakhimov M, Poluasheva G (2012) Water management in Khorezm: current situation and options for improvement (hydrological perspective). In: Martius C, Lamers J, Vlek P (eds) Cotton, Water. Salts and Soums - economic and ecological restructuring in Khorezm, Uzbekistan, Springer, Heidelberg, pp 69-92

Turlach BA, Weingessel A (2011) Quadprog: functions to solve quadratic programming problems. R package version 1.4-11 ftp://tp.uni-bayreuth.de/pub/math/statlib/R/CRAN/doc/packages/quadprog.pdf. Accessed 15 November 2012

United States Department of Agriculture (2012) Economic policy and cotton in Uzbekistan, A report from the Economic Research Service., http://www.ers.usda.gov/media/935015/cws12h01.pdf Accessed 11 January 2013

Vakhabov A, Muminov N, Djurakhanov F, Karimov A (2006) The accession of Uzbekistan to the world trade organization: challenges and opportunities for the food processing industry. Uzbekistan Economy. Stat Anal Rev 4:97-102, http://www.uzbearingpoint.com/files/3/a43.pdf. Accessed 15 November 2012

Vann Assche K, Hornidge AK (2012) Knowledge in rural transitions: formal and informal underpinnings of land governance in Khorezm. ZEF Working paper series 98., http://www.zef.de/fileadmin/webfiles/downloads/zef_wp/wp98.pdf. Accessed 12 June 2013

Welch F (1970) Education in production. J Polit Econ 78:35-59

doi:10.1186/s40100-014-0007-0

Cite this article as: Karimov: Factors affecting efficiency of cotton producers in rural Khorezm, Uzbekistan:

Re-examining the role of knowledge indicators in technical efficiency improvement. Agricultural and Food Economics $20142: 7$. 